\title{
Study of Electrochemical Oxidation of Catechol in the Presence of Sulfanilic Acid at Different pH
}

\author{
Md. Abdul Motin, ${ }^{a,}$ Md. Alim Uddin, ${ }^{a}$ Palash K. Dhar, ${ }^{a}$ \\ M.A. Hafiz Mia ${ }^{a}$ and Md. Abul Hashem ${ }^{b}$ \\ ${ }^{a}$ Department of Chemistry, Khulna University of Engineering \& Technology (KUET), \\ Khulna 9203, Bangladesh \\ ${ }^{b}$ Department of Leather Engineering, Khulna University of Engineering \& Technology \\ (KUET), Khulna 9203, Bangladesh
}

Received October 28, 2015; accepted December 19, 2016

\begin{abstract}
The electrochemical behavior of catechol in the presence of sulfanilic acid has been examined in aqueous solution with numerous $\mathrm{pH}$ values, different electrodes and different concentration of sulfanilic acid, using cyclic voltammetry, controlled potential coulometry and differential pulse voltammetry. The reaction of o-benzoquinone with sulfanilic acid in the second scan of potential was observed. It is assumed that the reaction occurred between the sulfonate group of sulfanilic acid and quinone, rather than between the amino group of sulfanilic acid and quinone. The products derived from the reaction are associated with electrons transfer at more negative potentials than those from catechols. The significance of catechol's $\mathrm{pH}$ in presence of sulfanilic acid was studied by varying $\mathrm{pH}$ from 2 to 9 . The concentration influence of sulfanilic acid with the fixed concentration of catechol $(2 \mathrm{mM})$ was determined from $2 \mathrm{mM}$ to $12 \mathrm{mM}$. The reaction was toughly affected by the $\mathrm{pH}$, as well as by the concentration of sulfanilic acid. The reaction was mostly promising in $2 \mathrm{mM}$ of sulfanilic acid and $2 \mathrm{mM}$ of catechol at $\mathrm{pH} 7$.
\end{abstract}

Keywords: voltammetry; controlled potential coulometry; electro-oxidation; sulfanilic acid; catechol.

\section{Introduction}

Catechols are well known in biological systems often as a reactive center of electrons transfer in the structure of many natural compounds and biologically reactive molecules, and they are produced in industrial scales as the precursor of pesticides, perfumes and pharmaceuticals [1]. The catechol skeleton also occurs in a variety of natural products, specially antioxidants [2]. The most well-known characteristic of catechols is that they can be easily oxidized, mainly due to their

\footnotetext{
* Corresponding author. E-mail address: abdulmotin75@yahoo.com
} 
antioxidant activity and low oxidation potentials [3]. The products of oxidation are the corresponding reactive and electron-deficient $o$-quinones. One of the most successful in situ generations of reactive $o$-quinones species is electrochemical oxidation [4]. There are many reports on electro-oxidation of catechols that produce $o$-quinones as reactive intermediates in many useful homogeneous reactions [5]. The quinones formed are quite reactive and can be attacked by a variety of nucleophiles $[4,5]$. The mechanism is dependent on some parameters, such as the nature of nucleophile (electron withdrawing or donating), electrolysis medium (solvent, acidity or $\mathrm{pH}$ ) and catechol type, etc.

Sulfanilic acid (p-aminobenzene sulphonic acid) is a light grey powder or crystal, slightly soluble in water, alcohol and ether. It is an inner salt, in which the amino group is neutralized by the sulfo group. It is used as an intermediate for colorants (dyes, food colors, and optical brightening agents), medicines and other organic synthesis [6]. It is converted to sulfanilamide, which is one of the basic materials to produce antibacterial sulfa drugs.

The electrochemical oxidation of catechols occurs in the presence of some other nucleophiles, such as methanol, 4-hydroxycoumarin, ethanol, 2-thiobarbituric acid, b-diketones, 4-hydroxy-6-methyl-2-pyrone, 2-thiouracil, dimedone, 4,7dihydroxycoumarin, 4,5,7-trihydroxycoumarin, 4-hydroxy-6-bromocoumarin, 3hydroxy coumarin, 4-hydroxy-6-methyl-a-pyrone, 4-hydroxy-6-methyl-2pyridone, nicotinamide and 4-hydroxycarbostyrile [7-16]. A few papers have been published on electrochemical oxidation of catechols with sulfanilic acids [17]. They have examined the electro catalytic effect of catechol with sulfanilic acid in only a Gc electrode at a single concentration of sulfanilic acid in $0.15 \mathrm{M}$ acetate solution. However, p-aminobenzene sulfonates are important biochemically compounds in this route, therefore, they strain detailed electrochemical studies of catechol in the presence of sulfanilic acid. In this paper, we have examined electrochemical behaviors of catechol in presence of sulfanilic acid with three different electrodes ( $\mathrm{Au}, \mathrm{Gc}$ and $\mathrm{Pt}$ ), comparatively higher concentrations of sulfanilic acid (2-12 mM), different $\mathrm{pH}(2-9)$ and scan rates.

\section{Experimental}

The used catechol and sulfanilic acid were of analytical grade (E-Merck). Catechol, and catechol with sulfanilic acid solutions of different concentrations were prepared in different $\mathrm{pH}$, using acetate or phosphate buffer solutions. Platinum and gold disks of $1.6 \mathrm{~mm}$ diameter (BASi) and Glassy Carbon disks of $3 \mathrm{~mm}$ diameter (BASi) were used as working electrodes for voltammetry. The working electrode used in controlled potential coulometry was an assembly of three carbon rods $(6 \mathrm{~mm}$ diameter and $4 \mathrm{~cm}$ length). The electrode surface was polished with $0.05 \mu \mathrm{m}$ alumina before each run. The auxiliary electrode was a platinum coil (BASi). The reference electrode was an $\mathrm{Ag} \mid \mathrm{AgCl}$ electrode (BASi). The working electrode was then polished on this surface, by softly pressing the electrode against the polishing surface in the end for 5-10 minutes. The electrode was then thoroughly washed with deionized water. At this point, the electrode 
surface would look like a shiny mirror. The potentiostat/galvanostat was $\mu$ Stat 400 (DropSens, Spain). Nitrogen gas was bubbled from the one-compartment cell before electrochemical run.

\section{Results and discussion}

\section{Electrochemical behavior of catechol and sulfanilic acid}

Voltammetric behavior of catechol in absence and presence of sulfanilic acid was measured by cyclic voltammetry $(\mathrm{CV})$, controlled potential coulometry (CPC) and differential pulse voltammetry (DPV). Fig. 1 (circle line) expresses the cyclic voltammogram of $2 \mathrm{mM}$ catechol of Gc $(3 \mathrm{~mm})$ electrode in a buffer solution of $\mathrm{pH} 3$ and a scan rate of $0.1 \mathrm{~V} / \mathrm{s}$. The cyclic voltammogram of catechol displays one anodic peak at $(0.48 \mathrm{~V})$ and a corresponding cathodic peak at $(-0.02 \mathrm{~V})$, connected to its transformation to $o$-quinone and vice-versa. Pure sulfanilic acid is electrochemically active having an anodic peak at $1.02 \mathrm{~V}$ and a corresponding cathodic peak at $0.25 \mathrm{~V}$ in the studied potential range (Fig. 1, dashed line).

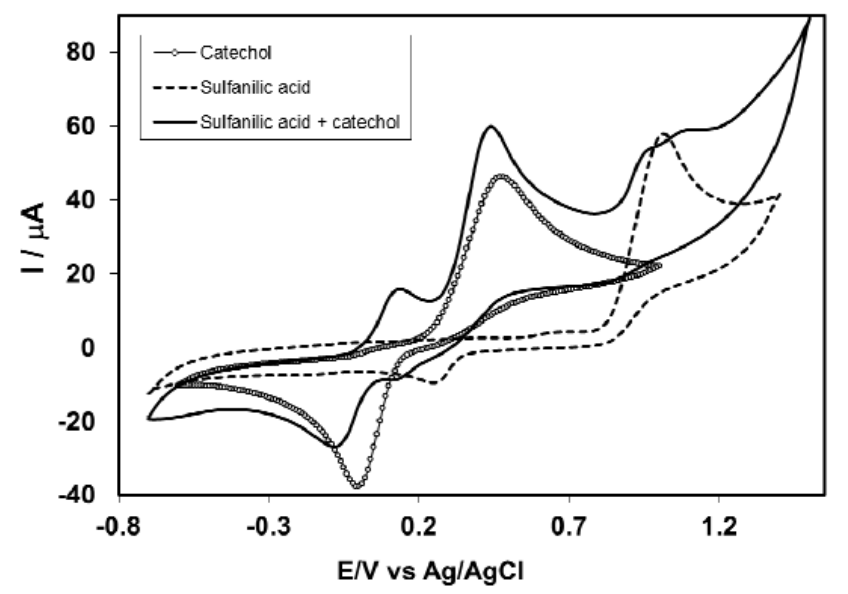

Figure 1. Cyclic voltammogram of $2 \mathrm{mM}$ catechol (circle line), $2 \mathrm{mM}$ sulfanilic acid (dashed line) and $2 \mathrm{mM}$ catechol with $2 \mathrm{mM}$ sulfanilic acid (deep solid line) of Gc electrode in a buffer solution $(\mathrm{pH} 3)$ at a scan rate of $0.1 \mathrm{~V} / \mathrm{s}\left(2^{\text {nd }}\right.$ cycle $)$.

Fig. 2 (deep solid line) shows the $\mathrm{CV}$ of catechol $(2 \mathrm{mM})$ in the presence of sulfanilic acid $(2 \mathrm{mM})$ in the second scan of potential in the same condition. The second cycle of potential catechol with sulfanilic acid shows three anodic peaks at $0.15 \mathrm{~V}, 0.44 \mathrm{~V}$ and $1.07 \mathrm{~V}$, and the corresponding two cathodic peaks at 0.08 $\mathrm{V}$ and $0.12 \mathrm{~V}$, respectively. The CV nature of catechol in presence of sulfanilic acid is irreversible. Upon addition of sulfanilic acid to a catechol solution, the cathodic peak $\mathrm{C}_{1}$ shifted negatively. Also, in the second cycle of potential a new anodic peak $A_{o}$ appears, and anodic peaks $A_{1}$ and $A_{2}$ shifted negatively.

The newly appearance of $A_{o}$ and shifting of $A_{1}, A_{2}$ and $C_{1}$ peaks positions in the presence of sulfanilic acid ascribe that this is due to the reaction of catechol with sulfanilic acid. This can be explained by considering nucleophilic attack of sulfanilic acid to o-benzoquinone. In the first scan of potential, the anodic peak of catechol in presence of sulfanilic acid is very similar to only catechol and only sulfanilic acid. But in the second scan, the potential appearance of a new peak 
$A_{o}$, and the shifting of $A_{1} A_{2}$ and $C_{1}$ peaks positions are indicative of a chemical reaction of sulfanilic acid (2) with the o-quinone (1a) produced at the surface of electrode. If the constituent is such that the potential for the oxidation of the product is lower, then, further oxidation of the product is lower, and further oxidation and further addition may occur [18]. In the case of catechol in presence of sulfanilic acid, the oxidation of sulfanilic acid substituting o-benzoquinone is easier than the oxidation of parent catechol. This behavior is in agreement with that reported by other research groups for similar electrochemically generated compounds, such as catechol and different nucleophiles [8-16, 18-20]. In the absence of other nucleophiles, water or hydroxide ion often add to the obenzoquinone [21].

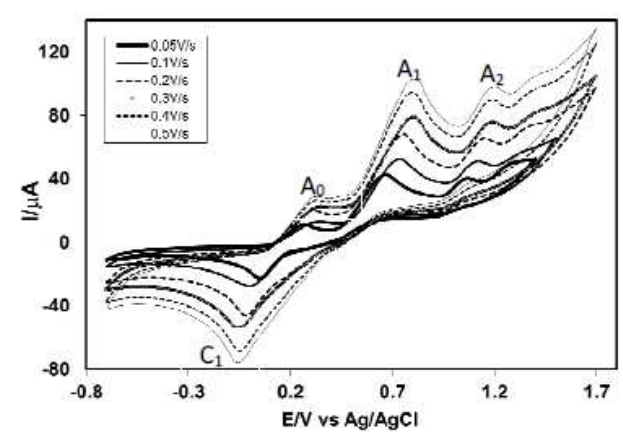

(a)

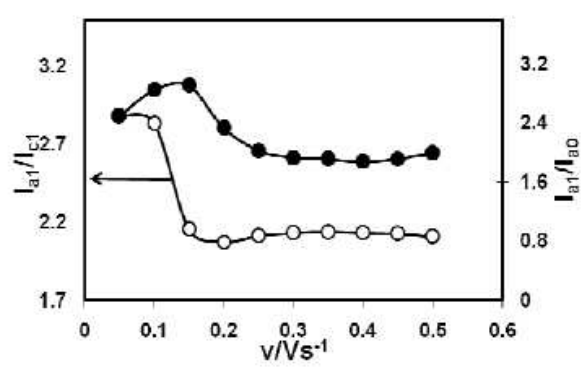

(c)

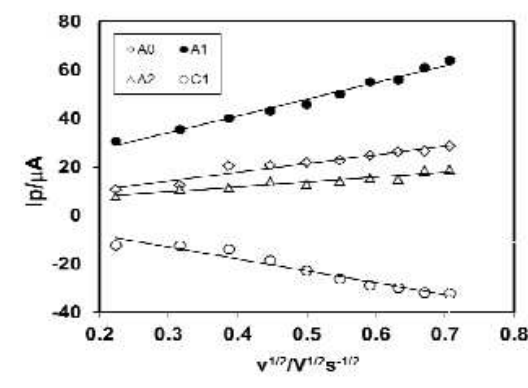

(b)

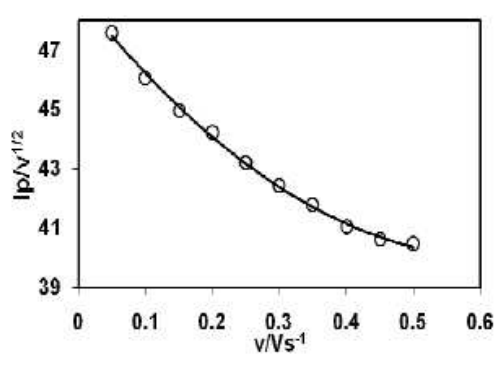

(d)

Figure 2. a) Cyclic voltammogram of $2 \mathrm{mM}$ catechol with $2 \mathrm{mM}$ sulfanilic acid in the second scan of potential at Gc electrode in a buffer solution ( $\mathrm{pH} 3$ ) at a scan rate of 0.05 $\mathrm{V} / \mathrm{s}-0.5 \mathrm{~V} / \mathrm{s}$. b) Plots of peak current vs. square root of scan rate in the same condition. The legend shows the symbol of oxidation and reduction peaks. c) Variation of peak current ratio of corresponding peaks $\left(\mathrm{I}_{\mathrm{pa} 1} / \mathrm{I}_{\mathrm{pc} 1}\right)$ and anodic peaks $\left(\mathrm{I}_{\mathrm{pa} 1} / \mathrm{I}_{\mathrm{pa} 0}\right)$ vs. scan rate in the same condition. d) Variation of peak current function $\left(\mathrm{Ip} / \mathrm{v}^{1 / 2}\right)$ versus scan rate in the same condition.

Fig. 2 (a) shows the $\mathrm{CV}$ of second cycle of $2 \mathrm{mM}$ catechol in presence of $2 \mathrm{mM}$ sulfanilic acid of $\mathrm{Gc}(3 \mathrm{~mm})$ electrode in a buffer solution $(\mathrm{pH} 3)$ at different scan rates. The peak current of both anodic and cathodic peaks increases with the increase of the scan rate. The cathodic peaks are shifted towards left, and the anodic peaks are to the right direction, with an increase in the scan rate. Fig. 2 (b) shows plots of the anodic and cathodic net peak currents of $2 \mathrm{mM}$ catechol with 2 $\mathrm{mM}$ sulfanilic acid for the second cycle against the square-root of the scan rates, where the net current means that the second peak subtracted from the first one by 
the scan-stopped method [18]. The nearly proportionality of the anodic and the cathodic peaks suggests that the peak current of the reactant at each redox reaction is controlled by a diffusion process. The corresponding peak current ratio $\left(\mathrm{I}_{\mathrm{pa} 1} / \mathrm{I}_{\mathrm{pc} 1}\right)$ vs. scan rate for a mixture of catechol and sulfanilic acid firstly decreases with an increasing scan rate, and then, after $0.15 \mathrm{~V} / \mathrm{s}$, it is almost unchanged (Fig. 2 (c)). The anodic peak current ratio $\left(\mathrm{I}_{\mathrm{pa} 0} / \mathrm{I}_{\mathrm{pa} 1}\right)$ vs. scan rate for a mixture of catechol and sulfanilic acid firstly increases, and then, after $0.15 \mathrm{~V} / \mathrm{s}$ scan rate, it decreases (Fig. 2 (c)). On the other hand, the value of current function $\left(\mathrm{Ip} / \mathrm{v}^{1 / 2}\right)$ was found to decrease with an increasing scan rate (Fig. $2(\mathrm{~d})$ ). The exponential nature of the current function versus the scan rate plot indicates the ECE mechanism for the electrode process [9]. This confirms that the reactivity of o-benzoquinone (1a) towards sulfanilic acid (2) firstly increases at a slow scan rate, and then, at a higher scan rate, it decreases.

The existence of a subsequent chemical reaction between o-benzoquinone 1a and sulfanilic acid 2 is supported by the following evidence:

(i) In the presence of sulfanilic acid both $E_{p c 1}$ and $E_{p a 1}$ shifted negatively and $E_{p a 0}$ appeared during second cycle (Fig. 1); this could indicate that electrochemically generated $o$-benzoquinone $1 \mathrm{a}$ is partially removed by chemical reaction with sulfanilic acid (2).

(ii) Corresponding peak current ratio $\left(\mathrm{I}_{\mathrm{pc} 1} / \mathrm{I}_{\mathrm{pa} 1}\right)$ varies with potential sweep rate. In this case, a well-defined cathodic peak $\mathrm{C}_{1}$ is observed at a highest sweep rate. For lower sweep rates, the peak current ratio $\left(\mathrm{I}_{\mathrm{pc} 1} / \mathrm{I}_{\mathrm{pa} 1}\right)$ is less than one, and increases with an increasing sweep rate. This indicates departure from intermediate and arrival to a diffusion region with an increasing sweep rate [18].

(iii) Increase in the scan rate causes a decrease in the progress of the chemical reaction of (1a) with (2), during the period of recording the cyclic voltammogram, and therefore, a decrease in the peak current ratio $\left(\mathrm{I}_{\mathrm{pa0}} / \mathrm{I}_{\mathrm{pa}}\right)$ at a higher scan rate.

(iv) The current function, $\mathrm{I}_{\mathrm{p}} / v^{1 / 2}$ for $\mathrm{A}_{1}$, was found to be exponentially decreased with an increasing scan rate. This indicates that the reaction mechanism of the system was of ECE type (Scheme 1).

According to the results, it seems that the reaction of sulfanilic acid (2) to obenzoquinone (1a) leads to product 3. The oxidation of this compound (3) is easier than the oxidation of the parent molecule (1), by virtue of the presence of the electron donating amine group.

The CV of pure catechol in a buffer solution ( $\mathrm{pH} 3)$ at different scan rates is also observed. The proportionality of the anodic and cathodic peak current against the square-root of the scan rates suggests that the peak current of the reactant at each redox reaction is also controlled by the diffusion process.

\section{Influence of $\mathrm{pH}$}

The electrochemical behavior of catechol, both in the absence and presence of sulfanilic acid, was studied by examining the electrode response in a buffer solution of different $\mathrm{pH}$. Cyclic voltammetry detailing the oxidation of $2 \mathrm{mM}$ catechol in different $\mathrm{pH}$ at a scan rate of $0.1 \mathrm{~V} / \mathrm{s}$ was measured. In the buffer solution of $\mathrm{pH} 3$, catechol produced a well-developed reversible wave. The 
anodic peak potential of catechol shifted towards left with the increase of $\mathrm{pH}$. The electrochemical reaction of catechol occurring at $\mathrm{pH}$ below 7 is a twoproton, two-electron transfer process (Scheme 1). This behavior is in agreement with that reported by other research groups for catechol and its derivatives [19, 20].

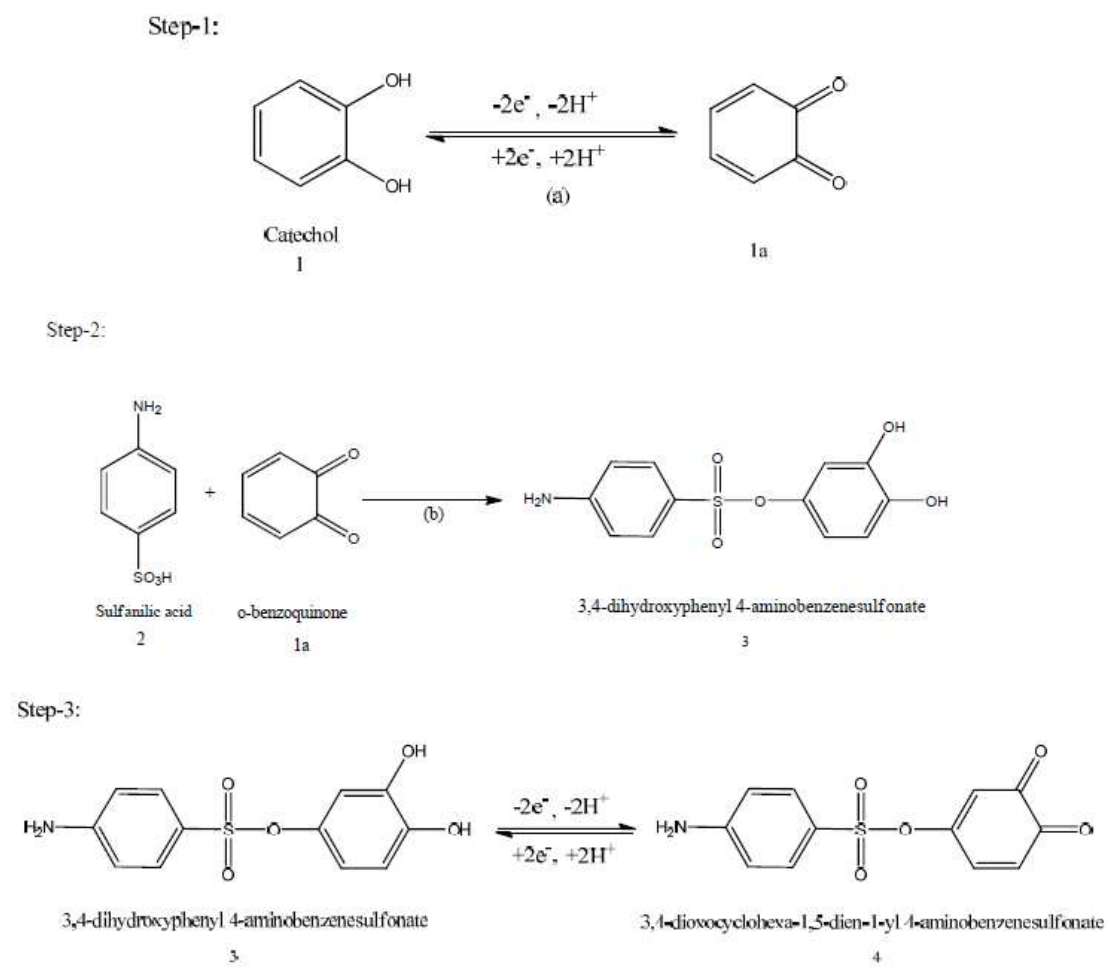

Scheme 1.

Cyclic voltammogram of catechol in presence of $2 \mathrm{mM}$ sulfanilic acid of $\mathrm{Gc}$ ( 3 $\mathrm{mM}$ ) electrode was studied at $\mathrm{pH}$ from 2 to 9 (Fig. 3 (a)). The voltammetric behavior of catechol at $\mathrm{pH} 9$ in the presence of $2 \mathrm{mM}$ sulfanilic acid shows that no new anodic peak appeared after repetitive cycling, indicating that the reaction between o-benzoquinone and sulfanilic acid has not occurred. In the $\mathrm{pH} 2-5$, a voltammetric new anodic peak appeared after repetitive cycling, whereas, in $\mathrm{pH}$ 7 , the cyclic voltammograms show a very small appearing peak. It was thus suggested that o-benzoquinone undergoes an attack by sulfanilic acid at $\mathrm{pH} 2-5$, reflecting that the voltammetric new anodic peak appeared after repetitive cycling. In this condition ( $\mathrm{pH} 2-5)$, it is expected that the nucleophilic property of amine groups may be diminished through protonation. However, sulfonate can also act as a weak nucleophile [6]. Now, a question arises of which part of sulfanilic acid (amine or sulphonate) will react with catechol. From the voltammogram, it is seen that the reaction of sulfanilic acid with catechol is favored in acid media, rather than neutral or basic media. Therefore, the reaction feasibility between protonated amine and quinone becomes weaker, and the reaction feasibility between sulfonate and quinone becomes stronger.

Fig. 3 (b) shows the plot of oxidation peak potential, $E_{\mathrm{p}}$ values against $\mathrm{pH}$. The slopes of the plot were graphically determined as the anodic peaks $(36 \mathrm{mV} / \mathrm{pH}$ for second anodic peak $A_{1}$ or $38 \mathrm{mV} / \mathrm{pH}$ for appeared peak $A_{0}$ ) at $0.1 \mathrm{~V} / \mathrm{s}$, which 
is close to the theoretical value for two-electron, two-proton transfer process. This indicates that both the oxidation of catechol and catechol-sulfanilic acid adduct proceeded via the $2 \mathrm{e}^{-} / 2 \mathrm{H}^{+}$processes. This also suggests that, during the reaction, not only electrons but also protons are released from the catecholsulfanilic acid adduct. Other research groups also reported similar behavior for catechol and its derivatives [17-20]. The peak current of the redox couple also is found to be dependent upon pH. Fig. 3 (c) shows the plot of oxidation peak ( $\mathrm{A}_{0}$ and $\mathrm{A}_{1}$ ) current, $I_{\mathrm{p}}$ against the $\mathrm{pH}$ of the solution.

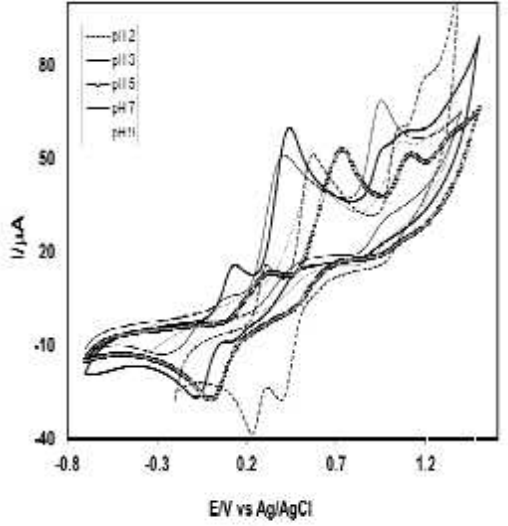

(a)

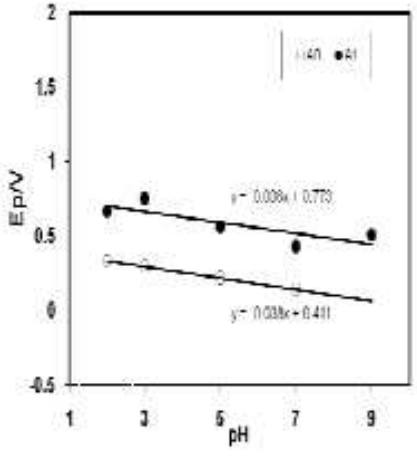

(b)

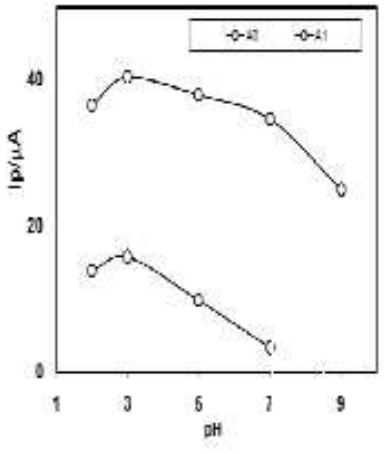

(c)

Figure 3. a) Cyclic voltammogram of $2 \mathrm{mM}$ catechol with $2 \mathrm{mM}$ sulfanilic acid of Gc (3 mm) electrode in different $\mathrm{pH}(2,3,5,7$ and 9) at a scan rate of $0.1 \mathrm{~V} / \mathrm{s}$. b) Plots of peak potential vs. $\mathrm{pH}$ in the same condition. c) Plots of peak current vs. $\mathrm{pH}$ in the same condition. The meanings of symbol $\mathrm{A}_{0}$ and $\mathrm{A}_{1}$ are similar to those of Fig. 2.

From Fig. 3 (c), it is seen that the maximum peak current is obtained at pH 3. At this $\mathrm{pH}$, the difference between the peak current ratio $\left(\mathrm{I}_{\mathrm{pCl}} / \mathrm{I}_{\mathrm{pA} 1}\right)$ in the presence and absence of sulfanilic acid is maximum. Consequently, in this study, the buffer solution of $\mathrm{pH} 3$ has been selected as a suitable medium for the electrochemical study of catechols in the presence of sulfanilic acid. This ascribed that the electrochemical oxidation of catechol in presence of sulfanilic acid is facilitated in acidic media.

\section{Concentration effect of sulfanilic acid}

Fig. 4 shows the variation of voltammogram pattern by the addition of different concentrations of sulfanilic acid $(2,4,6,8,10$ and $12 \mathrm{mM})$ into a fixed concentration of catechol $(2 \mathrm{mM})$ of $\mathrm{Gc}(3 \mathrm{~mm})$ electrode at $\mathrm{pH} 3$ and a scan rate of $0.1 \mathrm{~V} / \mathrm{s}$.

The anodic peaks shifted positively, and a new peak appeared at $\sim 0.15 \mathrm{~V}$ upon the addition of sulfanilic acid, which suggests the formation of a catecholsulfanilic acid adduct. The current intensity of the newly appeared anodic and cathodic peak increases with the increase of the sulfanilic acid composition. At a higher concentration of sulfanilic acid $(>2 \mathrm{mM})$, another new peak appeared at $0.39 \mathrm{~V}$. At this condition, the anodic peak current proportionally varies with the scan rate. This suggests that the peak current of the species at higher concentrations is controlled by the adsorption process. At higher concentrations 
of sulfanilic acid $(>2 \mathrm{mM})$, the excess electroactive sulfanilic acid may be deposited on the electrode surface, and it can occur the formation of some side reaction or polymerization reaction at the electrode surface with the abundance of sulphanilic acid. The reaction of catechol in presence of sulfanilic acid was favorable in $2 \mathrm{mM}$ of sulfanilic acid, $2 \mathrm{mM}$ catechol and at $\mathrm{pH} 7$.

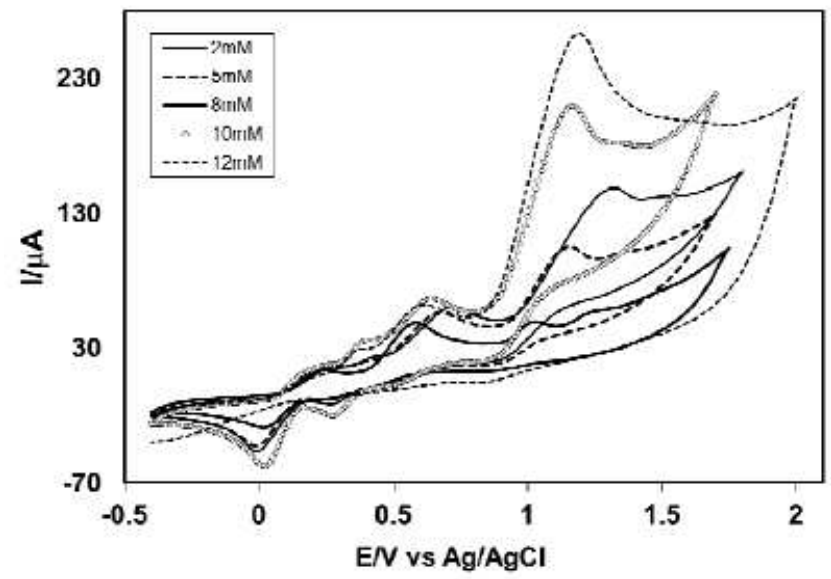

Figure 4. $\mathrm{CV}$ of composition changes of sulfanilic acid (2, 5, 8, 10 and $12 \mathrm{mM})$ with fixed $2 \mathrm{mM}$ catechol of Gc electrode at $\mathrm{pH} 3$ and a scan rate of $0.1 \mathrm{~V} / \mathrm{s}$.

\section{Effect of electrode materials}

Electrochemical properties of catechol in absence and presence of sulfanilic acid were examined by different electrodes, such as $\mathrm{Gc}$, Au and $\mathrm{Pt}$, at different $\mathrm{pH}$. The Cyclic voltammograms of $2 \mathrm{mM}$ catechol with $2 \mathrm{mM}$ sulfanilic acid at Gc, $\mathrm{Au}$ and Pt electrodes are shown in Fig. 5.

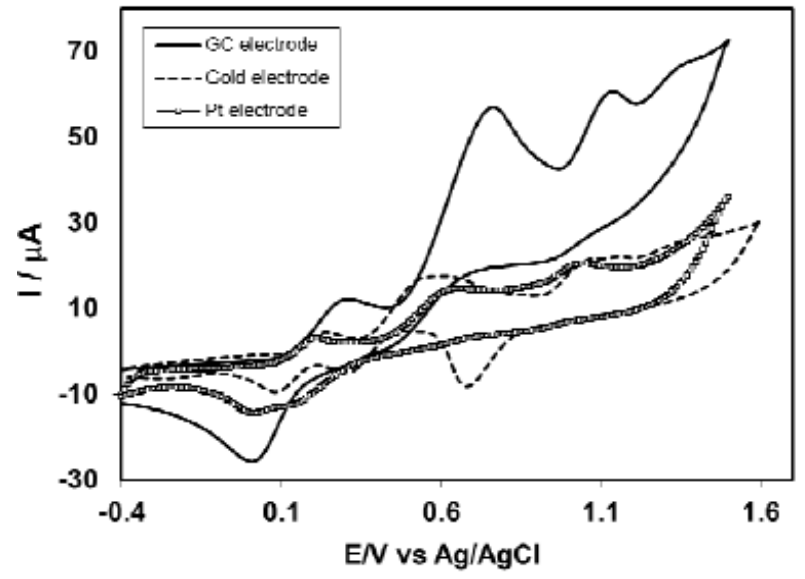

Figure 5. Cyclic voltammogram (CV) of $2 \mathrm{mM}$ catechol with $2 \mathrm{mM}$ sulfanilic acid in GC electrode $(3.0 \mathrm{~mm})$, gold electrode $(1.6 \mathrm{~mm})$ and platinum electrode $(1.6 \mathrm{~mm})$ at $\mathrm{pH}$ 3 and a scan rate of $0.1 \mathrm{~V} / \mathrm{s}$.

The nature of voltammograms, the peak position and current intensity for the studied systems are somewhat different for different electrodes, although the diameter of Gc electrode $(3 \mathrm{~mm})$ is higher than $\mathrm{Au}$ and $\mathrm{Pt}(1.6 \mathrm{~mm})$. The $\mathrm{CV}$ at $\mathrm{Au}$ electrode is significantly different from those of the Gc and Pt electrodes. The $\mathrm{Au}$ electrode shows four anodic and three cathodic peaks for the second scan. In 
its turn, the Gc electrode shows three anodic and two cathodic peaks for the second scan of potential, whereas the Pt electrode shows three anodic and one cathodic peak. Voltammetric measurements performed at a $\mathrm{Au}$ electrode in a simple buffer solution without catechol and with sulfanilic acid at $\mathrm{pH} 3$ showed a peak at $1.1 \mathrm{~V}$ to the formation of $\mathrm{Au}(\mathrm{III})$ hydroxide. Consequently, the third peak $(1.1 \mathrm{~V})$ of the $\mathrm{Au}$ electrode in presence of catechol and sulfanilic acid at $\mathrm{pH} 3$ is due to the oxidation of $\mathrm{Au}$ in the buffer solution. Similar behavior of oxidation of the $\mathrm{Au}$ electrode in different $\mathrm{pH}$ has been reported [21]. In the case of Gc and $\mathrm{Pt}$ electrodes, for the second cycle of potential, a new oxidation and reduction peak appears at a lower oxidation potential, which can be attributed to the oxidation of the adduct formed between the o-benzoquinone and sulfanilic acid. We have studied electrochemical properties of catechol with sulfanilic acid, for example, change of $\mathrm{pH}$, concentration, scan rate, etc., in detail, using $\mathrm{Pt}$ and $\mathrm{Au}$ electrodes. However, among the electrodes, the voltammetric response of the Gc electrode was better than that from Pt and Au electrodes in the studied systems. Therefore, in the paper, we have mainly discussed the properties of catechol with sulfanilic acid, using a Gc electrode.

\section{Subsequent cycles of $C V$ of catechol-sulfanilic acid}

Fig. 6 (a) shows the cyclic voltammogram of the first 15 cycles of $2 \mathrm{mM}$ catechol with $2 \mathrm{mM}$ sulfanilic acid of a Gc $(3 \mathrm{~mm})$ electrode in a buffer solution of $\mathrm{pH} 3$, for the potential range between $-0.7 \mathrm{~V}$ to $1.57 \mathrm{~V}$ at a $\mathrm{Gc}$ electrode. The voltammogram at the $0.1 \mathrm{Vs}^{-1}$ scan rate has three anodic peaks at $0.65 \mathrm{~V}, 1.05 \mathrm{~V}$, and $1.24 \mathrm{~V}$, and a cathodic peak at $0.03 \mathrm{~V}$, when considered the first scan (dashed line). In the subsequent potential cycles a new anodic peak appeared at $0.24 \mathrm{~V}$, and the intensity of the appeared anodic peak $\left(\mathrm{A}_{0}\right)$ current increased progressively on cycling, but the first (A1), second (A2) and third (A3) anodic peaks current decreased and shifted negatively on cycling. This can be attributed to the production of the catechol-sulfanilic acid adduct through the nucleophilic substitution reaction in the surface of the electrode (Scheme 1). The successive decrease in the height of the catechol oxidation and reduction peaks with cycling can be ascribed to the fact that the concentrations of catecholsulfanilic acid adduct formation increased by cycling, leading to a decrease of the concentration of catechol or quinone at the electrode surface.

Fig. 6 (b) shows the cyclic voltammograms of the first 15 cycles of $2 \mathrm{mM}$ Catechol of Gc $(3 \mathrm{~mm})$ electrode in a buffer solution of $\mathrm{pH} 7$ at a Gc electrode. The voltammogram at the $0.1 \mathrm{Vs}^{-1}$ scan rate has one anodic peak at $0.39 \mathrm{~V}$ and a cathodic peak at $0.02 \mathrm{~V}$ (dashed line). In the subsequent potential cycles no new anodic peak appeared. The reason for this may be that catechol showed one anodic and corresponding cathodic peak related to its transformation to $O$ quinone (Scheme 1).

During the repetitive cycling of potential, the anodic and cathodic peak current ratio are nearly unity (Fig. 6 (b)), which can be considered as criteria for the stability of o-quinone produced at the surface of the electrode [17], because they are too slow. In other words, any hydroxylation or dimerization [22-28] reactions are too slow, and that can be observed in the time-scale of cyclic voltammometry 
[17]. In basic solutions, the peak current ratio is less than unity and decreases with the increase in $\mathrm{pH}$, as well as with a decrease in the potential sweep rate. These can be related to the coupling of anionic or dianionic forms of catechols that are enhanced by an increase in the $\mathrm{pH}$ with o-quinones (dimerization reaction) [17].

a)

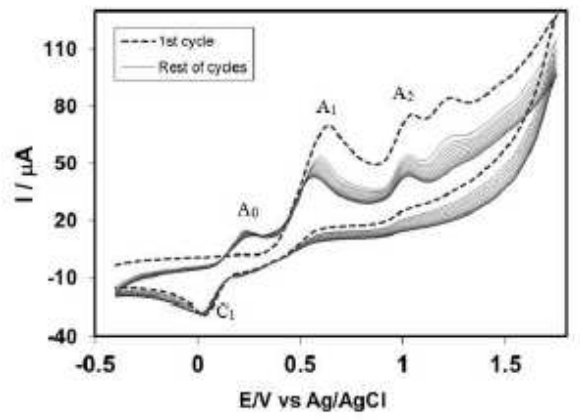

b)

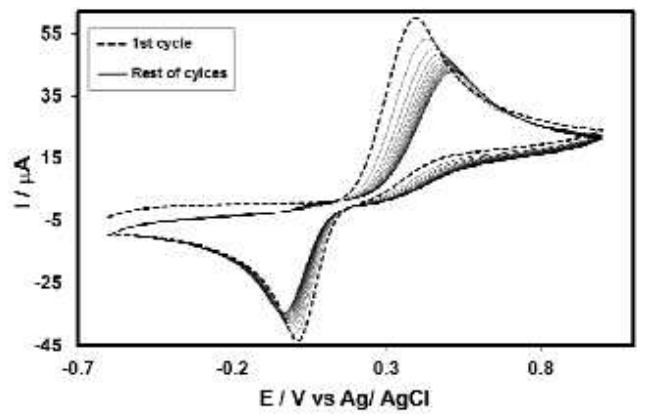

Figure 6. a) Cyclic voltammogram of $2 \mathrm{mM}$ sulfanilic acid with $2 \mathrm{mM}$ catechol of Gc (3 $\mathrm{mm}$ ) electrode in the buffer solution of $\mathrm{pH} 3$ at a scan rate of $0.1 \mathrm{~V} / \mathrm{s}$ ( 15 cycles). The appeared anodic peak current $\left(\mathrm{A}_{0}\right)$ increased with the iteration scan from the first cycle. b) $\mathrm{CV}$ of $2 \mathrm{mM}$ catechol in the buffer solution of $\mathrm{pH} 3$ at a scan rate of $0.1 \mathrm{Vs}^{-1}(15$ cycles). Figs. 6 (a) and (b) show first cycle (dashed line) and the rest of the cycles (solid line).

Controlled-potential coulometry was performed in an aqueous solution containing $0.50 \mathrm{mM}$ of catechol and $1 \mathrm{mM}$ of sulfanilic acid at $0.5 \mathrm{~V}$ in $\mathrm{pH} 7$. The electrolysis progress was monitored by cyclic voltammetry (Fig. 7). As Fig. 7 shows, during the course of coulometry, the peaks $A_{0}$ appeared and the height of the $A_{0}$ peak was increased to the advancement of coulometry, parallel to the decrease in height of anodic peaks $A_{1}, A_{2}$ and $A_{3}$.

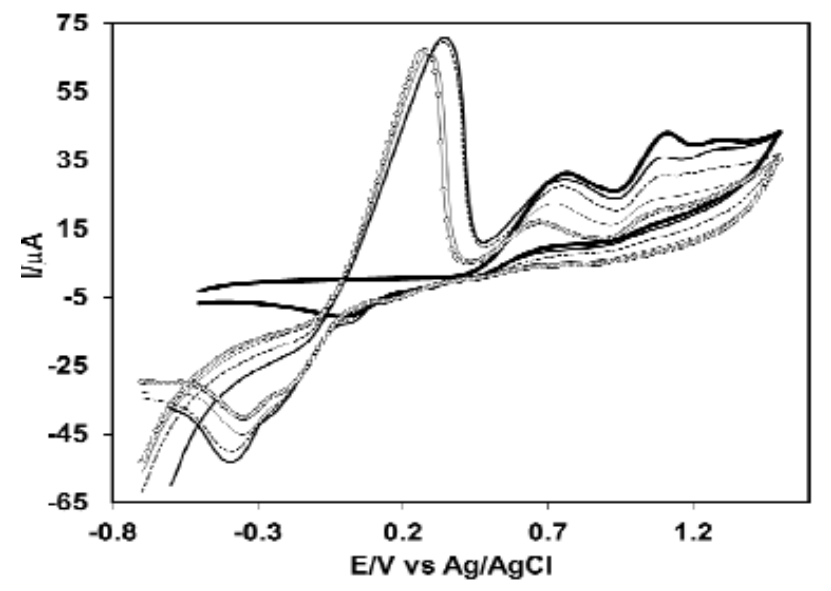

Figure 7. Cyclic voltammogram of $0.5 \mathrm{mM}$ catechol in presence of $1 \mathrm{mM}$ sulfanilic acid of Gc electrode during controlled potential coulometry at $0.5 \mathrm{~V}$ in $\mathrm{pH} 3$ at a scan rate of $0.1 \mathrm{~V} / \mathrm{s}$ after consumption of $0-100 \mathrm{C}$.

These observations allow us to propose the pathway in Scheme 1 for the electrooxidation of catechol (1) in the presence of sulfanilic acid (2). According to our results, it seems that the 1,4 addition reaction of 2 to o-quinone (1a) (reaction (2)) is faster than other secondary reactions, leading to the intermediate 3 . The 
oxidation of this compound (3) is easier than the oxidation of the parent starting molecule (1) by virtue of the presence of the electron-donating group.

\section{Differential pulse voltammetry}

Differential pulse voltammetry (DPV) technique was applied to make the catechol-sulfanilic acid substitution reaction clearer. DPV obtained for $2 \mathrm{mM}$ catechol in the presence of $2 \mathrm{mM}$ sulfanilic acid in the second scan at different $\mathrm{pH}$ (2-9) was shown in Fig. 8. The peak current of the redox couple is also found to be dependent upon $\mathrm{pH}$. In the buffer solution of $\mathrm{pH} 2-3$, catechol gave a welldeveloped wave in the presence of sulfanilic acid (Fig. 8).

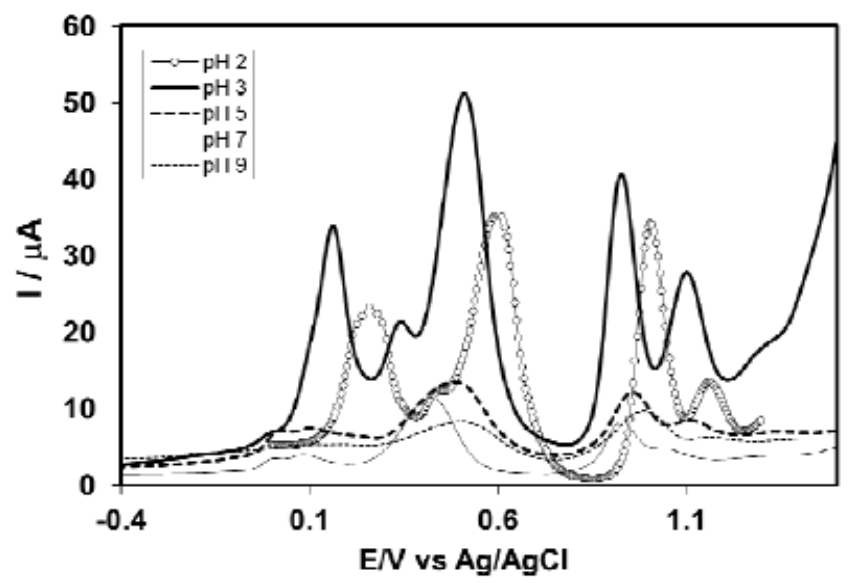

Figure 8. Differential pulse voltammogram (DPV) of $2 \mathrm{mM}$ catechol with $2 \mathrm{mM}$ sulfanilic acid of Gc electrode in the second scan of different $\mathrm{pH}(2,3,5,7$ and 9) at Epuls $0.02 \mathrm{~V}$, tpuls $20 \mathrm{~ms}$ and a scan rate of $0.1 \mathrm{~V} / \mathrm{s}$.

A sharp anodic adduct peak was obtained at $0.155 \mathrm{~V}$ in (Fig. 9), and other peaks $(0.50,0.92,1.09 \mathrm{~V})$ showed a corresponding oxidation of catechol in presence of sulfanilic acid, respectively, at $\mathrm{pH} 3$. But, in $\mathrm{pH}>3$ of the second scan of potential, the appeared anodic peak current intensity is very small, and in $\mathrm{pH} 9$, the second anodic peak was fully diminished. Therefore, the reaction of sulfanilic acid with catechol was favorable at $\mathrm{pH} \mathrm{3,} \mathrm{which} \mathrm{is} \mathrm{consistent} \mathrm{with} \mathrm{the}$ cyclic voltammogram.

Fig. 9 shows the DPV of deposition time change $(0,10,30,60,90$ and $120 \mathrm{~s})$ of $2 \mathrm{mM}$ catechol $+2 \mathrm{mM}$ sulfanilic acid of $\mathrm{pH}$ 3. From Fig. 9, it was seen that the increasing of deposition time from 0 to $120 \mathrm{~s}$ gradually leads to a new peak at $0.18 \mathrm{~V}$. When the deposition time increases $120 \mathrm{~s}$, further nucleophilic attack occurs and, consequently, more catechol-sulfanilic acid adduct leads to a decrease in the concentration of o-benzoquinone, and an increase in the concentration of catechol-sulfanilic acid adduct at the surface of electrode. For further increase of deposition time from $30 \mathrm{~s}$ to $120 \mathrm{~s}$, the first, second and third anodic peaks current decreases. This confirmed that, with the increase in time, the concentration of o-benzoquinone decreases and the concentration of catecholsulfanilic acid adduct increases at the surface of the electrode.

The effect of sulfanilic acid concentration on the differential pulse voltammogram of catechol was studied. Fig. 10 shows DPV for $2 \mathrm{mM}$ of a 
catechol solution containing a buffer $(\mathrm{pH} 3)$ in the presence of different concentrations of sulfanilic acid from 0 to $12 \mathrm{mM}$ at the surface of the Gc electrode.

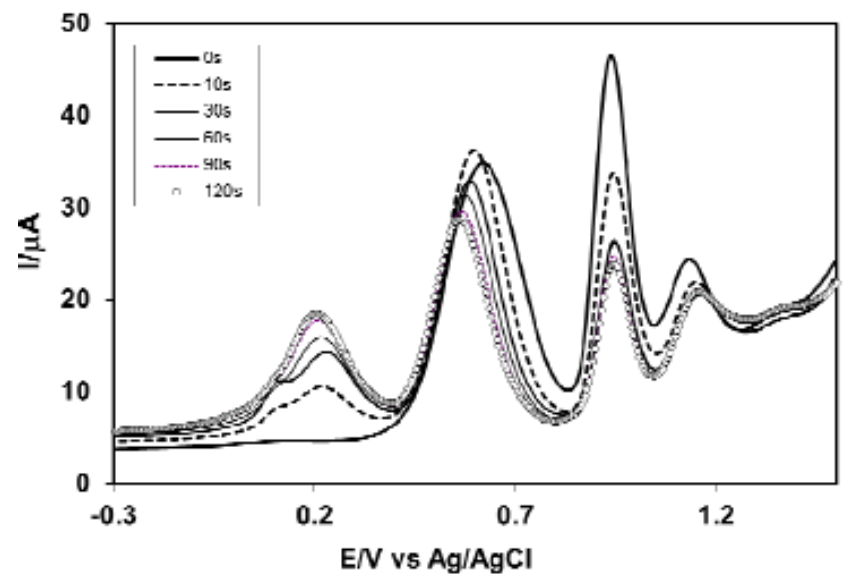

Figure 9. Differential pulse voltammogram (DPV) of deposition time change (0, 10, 30, $90,120 \mathrm{~s}$ ) of $2 \mathrm{mM}$ catechol with $2 \mathrm{mM}$ sulfanilic acid of $\mathrm{pH} 3$ at Epuls $0.02 \mathrm{~V}$, tpuls $20 \mathrm{~ms}$ and a scan rate of $0.1 \mathrm{Vs}^{-1}$.

As indicated in this figure, there are again some separated anodic peaks that appeared after the addition of sulfanilic acid into catechol, similar to what Fig. 8 shows. In this case, the increase in the concentration of sulfanilic acid from 5 to 8 $\mathrm{mM}$ leads to a decrease in first anodic peak current. For further increase of concentration from 10 to $12 \mathrm{mM}$, the first and second anodic peaks current gradually decreases. In a higher concentration of sulfanilic acid $(>5 \mathrm{mM})$, the nucleophilic substitution reaction takes place in a comparable degree, whereas a decrease in the concentration of sulfanilic acid $(<5 \mathrm{mM})$ favours a nucleophilic attack of sulfanilic acid towards the o-benzoquinone generated at the electrode surface. When more sulfanilic acid ( $>5 \mathrm{mM}$ ) is added into the catechol solution, the excess electro active sulfanilic acid is deposited on the electrode surface, and hence, there is some side reaction or polymerization reaction. The DPV behavior is consistent with $\mathrm{CV}$.

The FTIR spectra of the vibrational modes of the catechol-sulfanilic acid adduct, sulfanilic acid and catechol were studied. The sulfanilic acid showed the $\mathrm{N}-\mathrm{H}$ stretching sharp band at $3370 \mathrm{~cm}^{-1}$. The absorption peaks due to the $\mathrm{N}-\mathrm{H}$ stretching vibration almost remained at the same wave number of that from the catechol- sulfanilic acid adduct.

In this study, a different concentration of sulfanilic acid (2-12 $\mathrm{mM})$ and different $\mathrm{pH}$ (2-9) was sequentially used to determine the optimum condition for the nucleophilic substitution reaction of catechol with sulfanilic acid. The reaction was promising with $2 \mathrm{mM}$ of sulfanilic acid, $2 \mathrm{mM}$ of catechol and at $\mathrm{pH} 3$. Nematollahi et al. [17] reported the substitution reaction of catechol in presence of sulfanilic acid in a Gc electrode, at a single concentration of sulfanilic acid in $0.15 \mathrm{M}$ acetate solution. They predicted that a reaction would occur between the amine group of sulfanilic acid and quinone. They did not examine the concentration effect of sulfanilic acid and $\mathrm{pH}$ effect. From our study, it is seen 
that the reaction is found to be $\mathrm{pH}$ dependent, and it is mostly promising in $\mathrm{pH} 3$. Nucleophilic property of the amine group is diminished through protonation at $\mathrm{pH} 3$, so, the reaction feasibility between protonated amine and quinone becomes weaker, and the reaction feasibility between protonated sulfonate and quinone becomes stronger. Consequently, it is assumed that it occurred a reaction between the sulfonate group of sulfanilic acid and quinone (Scheme 1). From the above discussion, it is clear that the nucleophilic substitution reaction of catechol in presence of sulfanilic acid is the most favorable at $2 \mathrm{mM}$ of sulfanilic acid, 2 $\mathrm{mM}$ of catechol of the Gc electrode and at $\mathrm{pH} 3$.

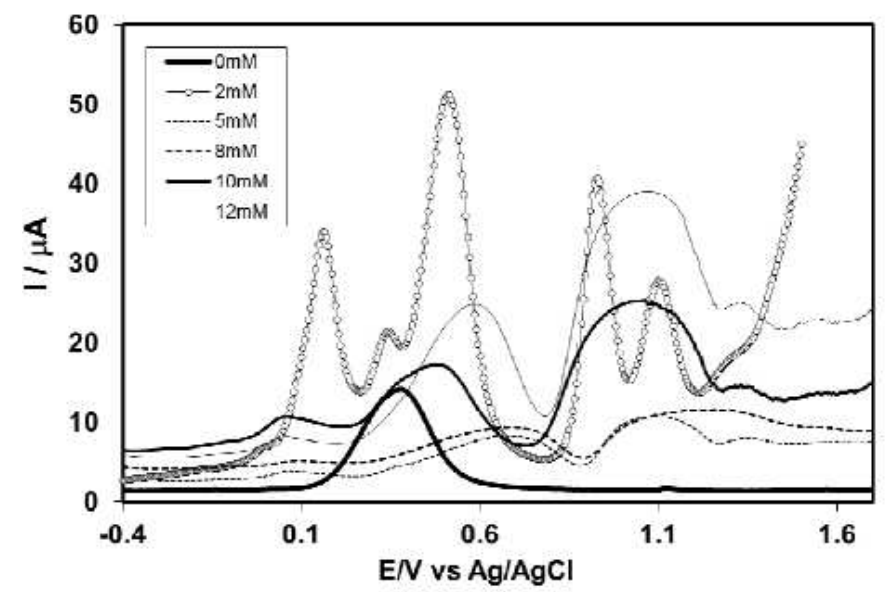

Figure 10. Differential pulse voltammogram (DPV) of composition change of sulfanilic acid $(0,2,5,8,10,12 \mathrm{mM})$ with the fixed composition of $2 \mathrm{mM}$ catechol in the second scan of pH3 at Epuls $0.02 \mathrm{~V}$, tpuls $20 \mathrm{~ms}$ of the Gc electrode and a scan rate of $0.1 \mathrm{Vs}^{-1}$.

\section{Conclusions}

The electrochemical properties of catechol in the absence and presence of sulfanilic acid were examined using cyclic voltammetry, controlled potential coulometry and differential pulse voltammetry. The anodic oxidation of catechol outcome in the formation of o-benzoquinone reacts with sulfanilic acid. The reaction yields transferred electrons at a more negative potential than that from catechol. It is assumed that the reaction occurred between the sulfonate group of sulfanilic acid and quinone, rather than between the amino group of sulfanilic acid and quinone. The peak current of the catechol- sulfanilic acid adduct at each redox reaction is governed by the diffusion process. The nucleophilic substitution reaction of catechol in presence of sulfanilic acid was most promising at $2 \mathrm{mM}$ of sulfanilic acid and at pH 3 in the Gc electrode. From the result, it can be concluded that the nucleophilic addition of sulfanilic acid happens through an ECE mechanism.

\section{Acknowledgements}

Thanks to Ministry of Science and Technology, Government of the People's Republic of Bangladesh, for giving financial support to this research project. 


\section{References}

1. Barner BA. Catechol. In: Paquette L, editor. Encyclopedia of Reagents for Organic Synthesis. New York: John Wiley \& Sons; 2004.

2. Khalafi L, Rafiee M. J Hazardous Mater. 2010;174:801.

3. Bisby RH, Brooke R, Navaratnam S. Food Chem. 2008;108:1002.

4. Rafiee M. Synlett. 2007;3:503.

5. Nematollahi D, Rafiee M, Fotouhi L. J Iran Chem Soc. 2009;6:448.

6. Morrision RT, Boyd RN. Organic Chemistry. 6th ed. Prentice Hall International, Inc; 1992.

7. Kiani A, Raoof JB, Nematollahi D, et al. Electroanalysis. 2005;17:1755.

8. Khalafi L, RafieeM, Shahbak M, et al. J. Chemistry. 2013;1:1.

9. Nematollahi D, Golabi SM. J Electroanal Chem. 2000;481:208.

10. Shahrokhian S, Hamzehloei A. Electrochem Commun. 2003;5:706.

11. Nematollahi D, Golabi SM. Electroanalysis. 2001; 3:1008.

12. Grujic Z, Tabakovic I, Trkovnic M. Tetrahedron Lett. 1976;52:4823.

13. Motin MA, Mia MAH, Islam MR, et al. Russian J Electrochim. 2015; Accepted.

14. Tabakovic I, Grujic Z, Bejtovic Z. J Heterocyclic Chem. 1983;20:635.

15. Nematollahi D, Forooghi Z. Tetrahedron. 2002;58:4949.

16. Golabi SM, Nourmohammadi F, Saadnia A. J Electroanal Chem. 2002;529:12.

17. Nematollahi D, Afkhami A, Mosaed F, et al. Res Chem Intermed. 2004;30:299.

18. Thibodeau PA, Paquette B. Free Radic Biol Med. 1999;27:1367.

19. Belenky P, Bogan KL, Brenner C. Trends Biochem Sci. 2007;32:9.

20. Mazzini S, Monderelli R, Ragg E, et al. J Chem Soc Perkin Trans. 1995;2:285.

21. M. Pasta, Mantia FL, Cui Y. Electrochim Acta. 2010;55:5561.

22. Motin MA, Uddin MA, Dhar PK, et al. J Electroanal Chem. 2015; Submitted.

23. Papouchado L, Petrie G, Adams RN. J Electroanal Chem. 1972; 38:389.

24. Papouchado L, Petrie G, Sharp JH, et al. J Am Chem Soc. 1968;90:5620.

25. Young TE, Griswold JR, Hulbert MH. J Org Chem. 1974;39:1980.

26. Brun A, Rosset R. J Electroanal Chem. 1974;49:287.

27. Stum DI, Suslov SN. Bio Zika. 1979;21;40.

28. Rayn MD, Yueh A, Yu CW. J Electrochem Soc. 1980;127;1489. 